\title{
La conservación-restauración de bienes culturales, una profesión en busca de regulación
}

\author{
María José Prieto Pedregal | conservadora-restauradora \\ URL de la contribución <www.iaph.es/revistaph/index.php/revistaph/article/view/3518>
}

\section{Sobre la falta de regulación}

Hace veintinueve años entró en vigor la Ley 16/1985, de 25 de junio, del patrimonio histórico español, a partir de la cual se fueron desarrollando legislaciones autonómicas. Según esta, los bienes integrantes del patrimonio cultural español son bienes de interés público general, siendo deber de los poderes públicos garantizar su conservación, así como promover su enriquecimiento y fomentar y tutelar el acceso adecuado de todos los ciudadanos a contemplar y disfrutar de los bienes comprendidos en él.

Nada concreta la ley general, sus revisiones (la última del año 2004), o las leyes autonómicas, sobre quiénes son los encargados de la intervención directa e indirecta sobre esos bienes para cumplir los deberes derivados de ella, más allá de la responsabilidad de la Administración. Alguna reglamentación recoge que las intervenciones sobre los bienes con especial categoría de protección deben ser realizadas "por personal cualificado", dejando ese punto de nuevo en la mayor de las indefiniciones. El conservador-restaurador se ha venido encargando de esas tareas, derivadas de actividades artísticas o artesanales que, en la actualidad, poco o nada tienen que ver con la moderna profesión.

La carencia de ordenación deja la puerta abierta a que se puedan causar graves perjuicios al patrimonio cultural, y por tanto a la colectividad. Casos de mala praxis se asoman a las noticias regularmente, creando una comprensible alarma social. Éstos ponen de relieve la desprotección de los bienes y de los usuarios, a quienes puede resultar difícil juzgar la calidad de las prestaciones que deben recibir.

Sin supervisión y control efectivos, en España no hay normativa que obligue a que los servicios y productos del sector de la conservación-restauración deban tener unas mínimas calidades y características. Las vigentes se refieren fundamentalmente a recursos económicos, de manera que las pequeñas empresas de profesionales cualificados suelen quedarse fuera de los proyectos públicos, bien por falta de capital, bien por otros problemas como pagos atrasados, asumibles por grandes constructoras.

\section{Sobre la enseñanza}

Hoy no existe en España un único título superior en Conservación y Restauración de Bienes Culturales. El profesorado actual tiene tan diversos perfiles como el de profesor de enseñanza secundaria o el de doctor universitario. Esto procura disparidad y comparaciones, no habiendo sido ni siquiera resuelta la homologación de planes anteriores de educación. Vivimos la absurda realidad de contar con profesionales titulados con una diplomatura por las antiguas Escuelas de Conservación y Restauración, a otros con la licenciatura en Bellas Artes con especialidad de conservación-restauración (en adelante, $\mathrm{C}+\mathrm{R}$ ), con la licenciatura en Bellas Artes con itinerario en $C+R$, con un título superior por las escuelas superiores de conservación y restauración, y, por último, con grado universitario en $\mathrm{C}+\mathrm{R}$.

Una de las consecuencias de la coexistencia de distintas titulaciones es el acceso a la función pública, que sitúa distintos títulos en distintos niveles administrativos, ejerciendo las mismas funciones o estando igualados en capacidades. Además se ha multiplicado la oferta de títulos propios, tanto de entidades públicas como privadas. Se ofrecen desde másteres universitarios hasta talleres de empleo o escuelas-taller, con el impulso europeo a proyectos de formación contra el desempleo. Especialmente preocupante es este último caso, que añade al mercado laboral un número creciente 
a debate El futuro de la conservación-restauración de bienes culturales | coordina Pilar Aguilar Solves

de pseudo-profesionales sin la formación mínima adecuada. No es de menor importancia el ejercicio profesional de titulados en humanidades a partir de la obtención de títulos de posgrado en conservación-restauración.

\section{La realidad del conservador-restaurador}

Esta profesión puede ser desempeñada, en la práctica, casi por cualquiera, titulado o no, con o sin la posesión de las competencias mínimas necesarias; por eso es urgente afrontar una regulación de forma inmediata. Muchos países de nuestro entorno, y otros más lejanos, han regulado o están en proceso de regulación esta profesión, e incluso los niveles anteriores de técnico de conservación-restauración, cuyos estudios se sitúan sólo a un paso por detrás del conservador-restaurador, en un nivel pre-universitario. Ese es el caso de Polonia, Italia o Eslovenia, entre otros.

Profesiones cercanas a nuestro ámbito abarcan competencias no bien definidas ni repartidas. Sirva como ejemplo la figura del arquitecto, quien dirige en solitario los proyectos de intervención, no sólo arquitectónicos, sino integrales. No está el conservador-restaurador igualado ni en responsabilidad ni en toma de decisiones en las direcciones técnicas de las obras. Lo mismo ocurre con el conservador de museos, colecciones, galerías y otras entidades.

Los colectivos de estudiantes y profesionales no han recibido más que desinterés por parte de la Administración en sus demandas. El descontento y desánimo entre ellos provoca un creciente abandono de la actividad por la precariedad laboral, la falta de perspectivas y el escaso reconocimiento económico y social. Últimamente asistimos a un continuo flujo de emigración de profesionales cualificados, con la pérdida de inversión y de capital humano que ello supone.

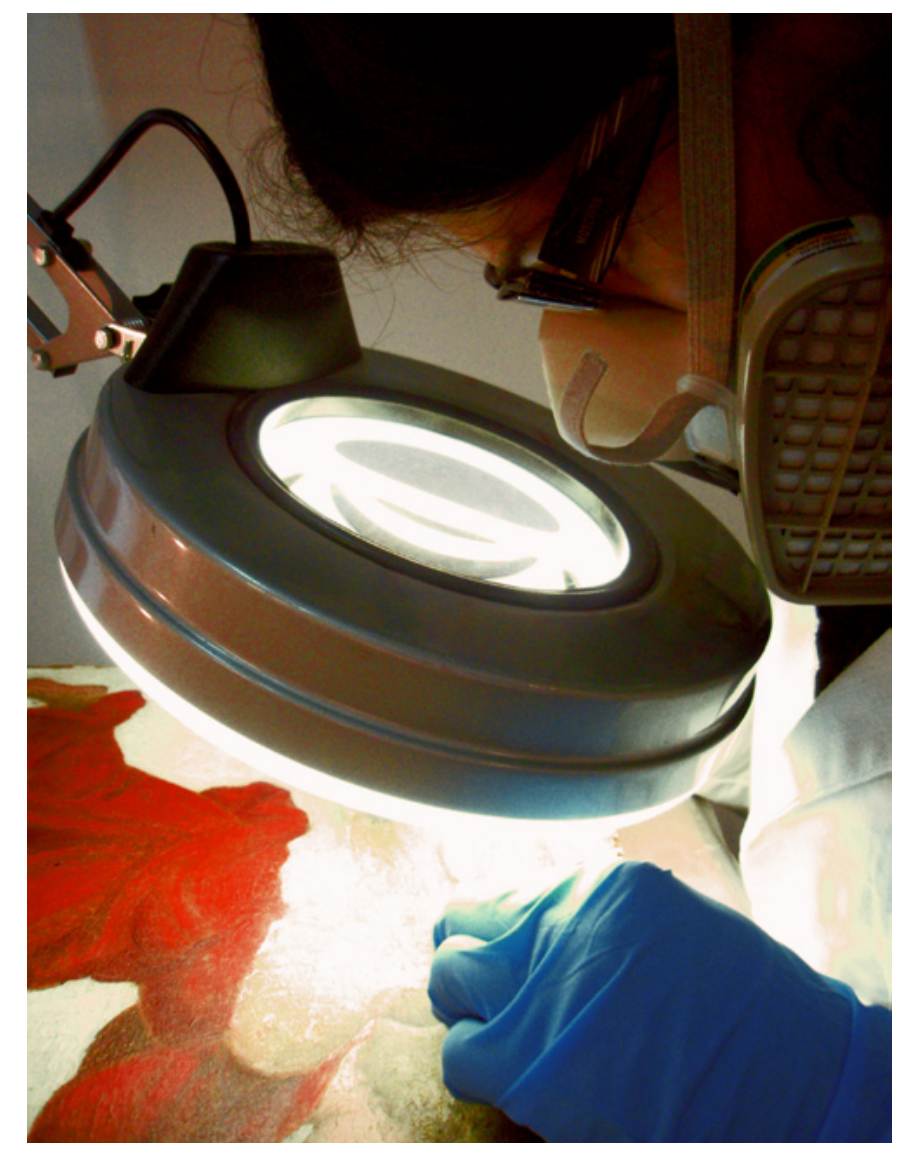

El trabajo del conservador-restaurador requiere de cualificación y responsabilidad | foto María José Prieto Pedregal

\section{¿Qué hacemos ahora?}

La necesidad y las propuestas de regulación no son nuevas. La Confederación Europea de Organizaciones de Conservadores y Restauradores es el organismo que, desde 1991, nos representa la profesión del conservador-restaurador a nivel europeo.

Es la voz de más de 5.000 conservadores-restaura- 
a debate El futuro de la conservación-restauración de bienes culturales | coordina Pilar Aguilar Solves

dores pertenecientes a asociaciones de países de la Unión Europea, entre ellas ACRE y CRAC (Associació Professional de Conservadors Restauradors de Catalunya).

El 1 de marzo de 2002, en asamblea general, ECCO definió las competencias de la profesión en su documento Directrices Profesionales: profesión, código ético y requisitos básicos para la educación en Conservación y Restauración. En él se especifica que, respecto a los bienes patrimoniales, el conservador-restaurador lleva a cabo y se responsabiliza del planteamiento estratégico, el examen y diagnóstico, la elaboración de los planes de conservación y de las propuestas de intervención, la conservación preventiva, los tratamientos de conservación-restauración y la documentación.

Existen ya amplias bases y trabajos desarrollados para poder organizar desde la educación mínima deseable hasta las tareas y áreas propias de los conservadores-restauradores. Es ineludible que la regulación se extienda a Europa para procurar el intercambio de profesionales, conocimientos y técnicas, que beneficiaría la misión de salvaguarda de nuestro patrimonio.

El asociacionismo, tradicionalmente asignatura pendiente en nuestro colectivo, está siendo y puede ser la herramienta más útil en todo este proceso. Apelemos como colectivo, con un objetivo claro de ordenación, a la voluntad de escuchar, dialogar, reglamentar y regular de la Administración para conseguir la tan necesaria regulación. 
_a debate El futuro de la conservación-restauración de bienes culturales | coordina Pilar Aguilar Solves

\section{BIBLIOGRAFÍA}

- BLACKMAN, C. (2007) España: La Laguna Europea. Conservadores en Europa. En Restauración \& Rehabilitación. Valencia: Editorial Universidad Politécnica de Valencia, n. ${ }^{\circ} 105$, pp. 18-19

- ECCO Professional Guidelines. En ECCO: European Confederation of Conservator-Restorers' Organisations [en línea] <http://www.ecco-eu.org/about-e.c.c.o./professional-gui delines.html> [consulta: 05/07/2014]

- GENERIC name of profession-Conservator/Conservatorrestorer/Restorer/Renovator. En Regulated professions database [en línea]. European Commission <http://ec. europa.eu/internal_market/qualifications/regprof/index. cfm?action=profession\&id_profession $=12061 \&$ tab $=$ countries \& quid=2\&mode=asc\&maxRows=*\#top> [consulta: 05/07/2014]

- HUELVES, E. (2013) ¿A qué esperan para regularizar la restauración del Patrimonio? Cuarto Poder [en línea], 30/3/2013, Cultura. Otro milagro <http://www.cuartopoder.es/ otromilagro/a-que-esperan-para-regularizar-la-restauraciondel-patrimonio/4670> [consulta: 05/07/2014]

- LEY 3/2013, de 18 de junio, de Patrimonio Histórico de la Comunidad de Madrid [publicada en BOCM núm. 144 de 19 de Junio de 2013 y BOE núm. 247 de 15 de Octubre de 2013]. En Noticias Jurídicas [en línea]. Grupo Wolters Kluwer España <http://noticias.juridicas.com/base datos/CCAA/507949-I-32013-de-18-jun-ca-madrid-patrimonio-historico.html\#a20http:// noticias.juridicas.com/base datos/CCAA/507949-I-3-2013-de18-jun-ca-madrid-patrimonio-historico.html\#a20> [consulta: 05/07/2014]

- LEY 16/1985, de 25 de junio, del Patrimonio Histórico Español. Boletín Oficial del Estado [en línea], n. ${ }^{\circ} 155$, de 29 de junio de 1985, pp. 20342-20352 <http://www.boe.es/buscar/ doc.php?id=BOE-A-1985-12534> [consulta: 05/07/2014]

- MOVILIDAD de los estudiantes, las personas en formación, los jóvenes voluntarios, los profesores y los formadores. En Europa: Síntesis de la legislación de la UE [en línea]. Comisión Europea <http://europa.eu/legislation_summaries/education training_youth/lifelong_learning/c11015_es.htm $>$ [consulta: 05/07/2014]

- EI PROCESO de Copenhague: una cooperación europea reforzada en materia de educación y formación profesionales. En Europa: Síntesis de la legislación de la UE [en línea]. Comisión Europea <http://europa.eu/legislation_summaries/ education_training_youth/vocational_training/ef00̄18_es.htm> [consulta: 05/07/2014]

- REAL DECRETO 1614/2009, de 26 de octubre, por el que se establece la ordenación de las enseñanzas artísticas superiores reguladas por la Ley Orgánica 2/2006, de 3 de mayo, de Educación. Boletín Oficial del Estado [en línea], n. ${ }^{\circ}$ 259, de 27 de octubre de 2009, pp. 89743-89752 <http://www.
boe.es/buscar/doc.php?id=BOE-A-2009-17005> [consulta: 05/07/2014]

- SENTENCIA del Tribunal Supremo (Sala de lo ContenciosoAdministrativo Sección Cuarta) de fecha 13/01/2012 respecto al Real Decreto 1614/2009, de 26 de octubre, por el que se establece la ordenación de las enseñanzas artísticas superiores reguladas por la Ley Orgánica 2/2006, de 3 de mayo, de Educación. Boletín Oficial del Estado [en línea], n. ${ }^{\circ}$ 71 , de 23 de marzo de 2012, páginas 25282-25282 < http:// www.boe.es/buscar/doc. php?id=BOE-A-2012-4020> [consulta: 05/07/2014]

- TERA, R. (2013) Curso de restauración 'online', un engaño al alumno y al patrimonio. El Confidencial [en línea], 25/03/2013 <http://www.elconfidencial.com/cultura/tribuna-deexpertos/2013/03/25/curso-de-restauracion-online-un-enganoal-alumno-y-al-patrimonio-10957/> [consulta: 05/07/2014]

- VIVIR y trabajar en el mercado interior. En Europa: Síntesis de la legislación de la UE [en línea]. Comisión Europea <http:// europa.eu/legislation_summaries/internal_market/living_and working_in_the_internal_market/index_es.h̄tm> [consulta: 05/ 07/2014]

- YOUTH employment: Commission proposes package of measures. En Empleo, asuntos sociales e inclusión [en línea]. Comisión Europea, DG de Empleo, Asuntos Sociales e Inclusión $<$ http://ec.europa.eu/social/main.jsp?langld=es\&catld=1036\&n ewsld=1731\&furtherNews=yes> [consulta: 05/07/2014] 